\title{
Decreased Gap Width in a Cylindrical High-Field Asymmetric Waveform Ion Mobility Spectrometry Device Improves Protein Discovery.
}

\section{SUPPORTING INFORMATION}

Kristian E. Swearingen, Jason M. Winget, Michael R. Hoopmann, Ulrike Kusebauch and Robert L. Moritz*

* To whom correspondence should be addressed:

Dr. Robert L. Moritz

Institute for Systems Biology

401 Terry Ave N, Seattle, WA 98109, USA

Email: robert.moritz@systemsbiology.org

Phone: +1-206-732-1200 


\section{SUPPORTING INFORMATION INDEX}

1. Extended Methods

2. Determining optimal FAIMS carrier gas flow rate

Figure S1. Determining optimal FAIMS carrier gas flow rate

3. Programmed FAIMS dwell time is not necessary due to instrumental latency.

Figure S2. Instrumental Latency in CV switching

4. FAIMS Libraries
A. Empirical Selection of CVs

Table S1. Protein discovery by extensive FAIMS fractionation

Figure S3. Empirical selection of compensation voltages.

B. Behavior of peptides in FAIMS

Figure S4. Separation of peptides in FAIMS.

C. FAIMS provides evidence of in-source fragmentation and charge stripping

Figure S5. FAIMS reveals charge stripping and in-source fragmentation.

5. Theoretically-predicted effects of changes to electrode shape and temperature
A. Effect of decreased gap width
B. Effect of electrode temperature
C. The relationship between FAIMS peak width and ion focusing

Figure S6. FAIMS peak width as a function of compensation voltage

6. Replicate LC-MS injections provide few novel protein identifications

Figure S7. Accumulation of novel peptide identifications with replicate analyses

7. Label-free quantification with FAIMS and isoelectric focusing

Figure S8. Comparison of normalized spectral abundance factor between sample fractionation techniques.

8. Supporting Information References 


\section{Extended methods}

\section{A. Sample Preparation}

Samples analyzed for comparison of different FAIMS configurations were prepared as follows: frozen pellets of BY4742 Saccharomyces cerevisiae were disrupted by cryolysis using a Retsch ball mill grinder. The resulting grindate was resuspended in $8 \mathrm{M}$ urea and $100 \mathrm{mM}$ ammonium bicarbonate $(A B C)$ by sonication and cleared by centrifugation. Protein concentration was determined by BCA assay (Pierce). The sample was reduced with $5 \mathrm{mM}$ tris(2-carboxyethyl)phosphine (TCEP) for $30 \mathrm{~min}$ at $55^{\circ} \mathrm{C}$, alkylated with $10 \mathrm{mM}$ iodoacetamide (IA) at room temperature in darkness for $60 \mathrm{~min}$, then diluted with $\mathrm{ABC}$ and Tris- $\mathrm{HCl} \mathrm{pH} 7.5$ to a final concentration of $0.75 \mathrm{mg} / \mathrm{mL}$ protein, $2 \mathrm{M}$ urea, $100 \mathrm{mM} \mathrm{ABC}$, and $50 \mathrm{mM}$ Tris- $\mathrm{HCl}$. The sample was digested for $16 \mathrm{~h}$ at $37^{\circ} \mathrm{C}$ with trypsin (Promega sequencing grade) at an enzyme:protein ratio of 1:50. After digestion the sample was diluted with $100 \mathrm{mM} \mathrm{ABC}$ to a protein concentration of $0.50 \mathrm{mg} / \mathrm{mL}$ and trifluoroacetic acid (TFA) was added to a concentration of $0.5 \%(\mathrm{v} / \mathrm{v})$. The sample was then desalted by solid phase extraction (SPE) on a tC18 cartridge (Waters Sep-Pak), dried down by rotary vacuum concentration, and resuspended in $2 \%$ acetonitrile (ACN) and $0.2 \%$ TFA to a nominal peptide concentration of $1 \mathrm{mg} / \mathrm{mL}$.

A new tryptic digest of the yeast sample was prepared for the experiments comparing FAIMS and OFFGEL electrophoresis (OGE). Grindate was re-suspended in $8 \mathrm{M}$ Urea and $100 \mathrm{mM} \mathrm{ABC}$. Proteins were reduced with $10 \mathrm{mM}$ dithiothreitol (DTT) at $55^{\circ} \mathrm{C}$ for $1 \mathrm{~h}$, and then alkylated with $50 \mathrm{mM} \mathrm{IA}$ at room temperature for $1 \mathrm{~h}$ in the dark. Protein was digested overnight at $37^{\circ} \mathrm{C}$ with trypsin (Promega sequencing grade) at an enzyme:protein ratio of 1:50. The reaction was acidified by addition of TFA to $\mathrm{pH}<2$. Peptides were desalted as above, split into two equal aliquots, and dried by rotary vacuum. Samples analyzed by FAIMS or without fractionation were resuspended in $0.1 \%$ TFA to a nominal peptide concentration of $0.75 \mathrm{mg} / \mathrm{mL}$. Samples fractionated by isoelectric focusing were resuspended in $\mathrm{ddH} 2 \mathrm{O}$. Isoelectric fractionation was performed on an Agilent 3100 OFFGEL fractionator according to the manufacturer's specification using $13 \mathrm{~cm}$ Immobiline DryStrip Gels (GE Healthcare), $\mathrm{pH}$ 3-10. Peptides were focused at $20 \mathrm{kVh}$ with a maximum current of $50 \mu \mathrm{A}$ and a maximum voltage set to $8000 \mathrm{~V}$. The resulting fractions were acidified by addition of TFA and desalted on a tC18 $\mu$ Elution plate (Waters), then dried by rotary vacuum and resuspended in $0.1 \%$ TFA. The $200 \mu \mathrm{g}$ fractions were each re-suspended in $200 \mu \mathrm{L}$ and the $20 \mu \mathrm{g}$ fractions were each re-suspended in $20 \mu \mathrm{L}$. Nine $\mu \mathrm{L}$ of each fraction were injected for analysis by nanoLC-MS/MS, corresponding to a nominal total of $9 \mu \mathrm{g}$ of peptides analyzed if sample loss was not considered.

A $2.0 \mathrm{mg} / \mathrm{mL}$ solution of bovine serum albumin (Pierce) was diluted to $1.0 \mathrm{mg} / \mathrm{mL}$ in $100 \mathrm{mM} \mathrm{ABC}$ and digested as described above. The peptides were dried under rotary vacuum and 
reconstituted in $50 \%$ methanol and $0.1 \%$ formic acid to a nominal concentration of $1 \mathrm{pmol} / \mathrm{\mu L}$.

\section{B. FAIMS instrumentation}

Analyses were performed on an LTQ-Orbitrap Elite (Thermo Fisher Scientific) enabled with a FAIMS device (Thermo Fisher Scientific). The FAIMS device has been described previously (1-2). Briefly, the device was comprised of two concentric cylindrical electrodes with an effective length of $25 \mathrm{~mm}$. The outer electrode had an inner radius of $9 \mathrm{~mm}$ and the inner electrode had an outer radius of $6.5 \mathrm{~mm}$, creating a gap of $2.5 \mathrm{~mm}$. The temperatures of the inner and outer electrodes could be independently regulated. We modified the device by replacing the inner electrode with a custom fabricated electrode having identical specifications as the original, except with a radius of $7.75 \mathrm{~mm}$, thus reducing the gap to $1.25 \mathrm{~mm}$ (3). The unmodified device was operated with a FAIMS carrier gas of $\mathrm{N}_{2}$ or $1: 1 \mathrm{~N}_{2}:$ He supplied at $3.5 \mathrm{~L} / \mathrm{min}$, a DV of $-5,000 \mathrm{~V}\left(E_{D}=-20 \mathrm{kV} / \mathrm{cm}\right)$, and the inner and outer electrodes maintained at $70^{\circ} \mathrm{C}$ and $90^{\circ} \mathrm{C}$, respectively. The modified FAIMS device with reduced gap was operated with a carrier gas of $\mathrm{N}_{2}$ supplied at $2.5 \mathrm{~L} / \mathrm{min}$, a DV of $-4,000 \mathrm{~V}\left(E_{D}=-32 \mathrm{kV} / \mathrm{cm}\right)$, and the inner and outer electrodes maintained at $70^{\circ} \mathrm{C}$ and $90^{\circ} \mathrm{C}$, respectively, or $90^{\circ} \mathrm{C}$ and $70^{\circ} \mathrm{C}$. Selection of FAIMS carrier gas flow rate was critical to optimal separation and ion transmission efficiency (3) (See Supporting Information section 2. Determining optimal FAIMS carrier gas flow rate). A fused silica capillary LC column with an I.D. of $75 \mu \mathrm{m}$ and fritted pulled tip with an I.D. of $15 \mu \mathrm{m}$ (Picofrit, New Objective) was interfaced with the FAIMS device via a HESI-II heated electrospray source (Thermo Fisher Scientific) that was modified to be used as a nanospray source (4). The source probe was set at depth "D", and the probe stage was centered and moved as far as possible in the direction of the entrance orifice. The capillary column extended $14 \mathrm{~mm}$ from the end of the probe. Sheath gas was enabled at 5 arbitrary units for the unmodified FAIMS device and 1 for the modified device. The HESI-II probe was not actively heated. Spray voltages were $1.6 \mathrm{kV}$ to $1.8 \mathrm{kV}$. (Applied voltages were $2.6 \mathrm{kV}$ to $2.8 \mathrm{kV}$ with a FAIMS entrance plate voltage of $1.0 \mathrm{kV}$ ).

\section{C. Infusion of a bovine serum albumin tryptic digest}

Infusion experiments were performed using an unpacked capillary column. A solution containing $100 \mathrm{pmol} / \mu \mathrm{L}$ bovine serum albumin (BSA) tryptic digest in $50 \%$ methanol and $0.1 \%$ formic acid was infused at $300 \mathrm{~nL} / \mathrm{min}$ using a $100 \mu \mathrm{L}$ syringe and the syringe pump on the mass spectrometer. Full scan MS1 spectra from 200-2000 m/z were collected in the Orbitrap with a resolving power of 120,000 at $400 \mathrm{~m} / \mathrm{z}$, a full scan automatic gain control (AGC) target of $1,000,000$ ions, and a maximum ion trap fill time of $200 \mathrm{~ms}$. Non-FAIMS data were collected using a nanospray 
source (Thermo Fisher Scientific) with a spray voltage of $1.8 \mathrm{kV}$. FAIMS data were collected with the modified nanospray source described above at a spray voltage of $1.8 \mathrm{kV}$. In order to directly compare ion transmission efficiency, variable ion trap fill times were corrected for by dividing the recorded ion current for each ion by the ion trap fill time for the spectrum in which it was recorded.

Four different FAIMS configurations were tested: the unmodified FAIMS device with $\mathrm{N}_{2}$ carrier gas; the unmodified FAIMS device with 1:1 $\mathrm{N}_{2}$ :He carrier gas; the modified, narrow-gap FAIMS device with $\mathrm{N}_{2}$ carrier gas and the inner and outer electrodes maintained at $70^{\circ} \mathrm{C}$ and $90^{\circ} \mathrm{C}$, respectively; and the modified FAIMS device with the inner and outer electrodes maintained at $90^{\circ} \mathrm{C}$ and $70^{\circ} \mathrm{C}$, respectively. The performance of the various configurations was assessed by collecting MS1 scans at CVs over the range of 0 to $-80 \mathrm{~V}$ using the FAIMS Compensation Voltage Ion Map Method in the XCalibur instrument control software (Thermo Fisher Scientific). The method only allows for a minimum CV step of $1.0 \mathrm{~V}$, which was sufficient resolution to characterize the unmodified electrode. In order to characterize the narrower FAIMS peaks produced by the modified FAIMS electrodes, two separate scanning experiments offset by $0.5 \mathrm{~V}$ were performed for each experimental condition and combined in order to obtain spectra at $0.5 \mathrm{~V}$ intervals. The FAIMS dwell time (a programmed delay in acquisition after switching CVs ) was set to $1 \mathrm{msec}$, the minimum allowed by the instrument control software. We determined that it was unnecessary to program a delay because the instrumental latency when switching between CVs was $\sim 125 \mathrm{msec}$, while the residence time of ions in the FAIMS device is $\sim 70 \mathrm{msec}$ with unmodified electrodes and $\sim 40 \mathrm{msec}$ with a reduced gap (see Supporting Information section 3. Programmed FAIMS dwell time is not necessary due to instrumental latency). FAIMS peaks (monoisotopic ion peak intensity with respect to $E_{C}$ ) were analyzed for a total of 60 peptide ions selected based on the following criteria: observed monoisotopic mass within $0.004 \mathrm{Da}$ of the predicted mass of a fully tryptic BSA peptide 7 or greater residues in length with no missed cleavages; $m / z>300$ and $<2000$; and a FAIMS peak clearly defined in all four FAIMS electrode configurations. FAIMS separation efficiency was quantified by peak capacity $P$, the number of FAIMS peaks (signal intensity with respect to $E_{C}$ ) that can be resolved in a given separation window, as

$$
P=\frac{\left|E_{c_{1}}-E_{c_{2}}\right|}{0.5 \times\left(w_{1}+w_{2}\right)}
$$

where $E_{c_{1}}$ and $E_{c_{2}}$ are the $E_{c}$ of the FAIMS peaks defining the separation window (in this case, the highest and lowest observed), and $w_{1}$ and $w_{2}$ are the respective FAIMS peak widths at half maximum. $P$ was estimated using peak width at half maximum in order to facilitate direct measurement of the peak rather than requiring peak fitting to calculate the full peak width at baseline. 
Some studies of cylindrical FAIMS have modeled FAIMS peaks by fitting them to a Gaussian distribution $(2,5)$, but FAIMS peaks generated by cylindrical electrodes are non-Gaussian (6-7). For the work presented here, the empirically determined peak width at half maximum was deemed a sufficient proxy for peak width since the performance of the various electrode configurations were being compared directly by analysis of peptide standard mixture. 


\section{D. NanoLC-MS/MS and nanoLC-FAIMS-MS/MS}

Chromatography was performed on a column with a fritted integrated tip (New Objective Picofrit, $360 \mu \mathrm{m}$ O.D., $75 \mu \mathrm{m}$ I.D., $15 \mu \mathrm{m}$ I.D. tip) packed in-house with a $20 \mathrm{~cm}$ bed of $\mathrm{C} 18$ silica (Dr. Maisch ReproSil-Pur C18-AQ, 120Å pore, $3 \mu \mathrm{m}$ particle size; Ammerbuch-Entringen, Germany). Prior to loading on the column, sample was loaded onto a trap consisting of a fritted capillary $(360 \mu \mathrm{m}$ O.D., $150 \mu \mathrm{m}$ I.D.) packed with a $1 \mathrm{~cm}$ bed of the same stationary phase. For each run in the experiments comparing FAIMS electrode configurations, $2 \mu \mathrm{g}$ of tryptic peptides were injected onto the trap and washed with loading buffer ( $2 \% \mathrm{v} / \mathrm{v}$ acetonitrile and $0.2 \% \mathrm{v} / \mathrm{v}$ trifluoroacetic acid in water) at $6 \mu \mathrm{L} / \mathrm{min}$ as provided by an Agilent $1100 \mathrm{HPLC}$ with electronically controlled split flow. HPLC mobile phase (Solvent $A=0.1 \% \mathrm{v} / \mathrm{v}$ formic acid in water, solvent $B=0.1 \% \mathrm{v} / \mathrm{v}$ formic acid in acetonitrile) was supplied at $500 \mathrm{~nL} / \mathrm{min}$ by an Agilent $1100 \mathrm{HPLC}$ with electronically controlled split flow. The gradient was $5 \% \mathrm{~B}$ to $35 \% \mathrm{~B}$ over $120 \mathrm{~min}$, followed by a $20 \mathrm{~min}$ wash at $80 \% \mathrm{~B}$ and a 30 min re-equilibration step at $5 \% \mathrm{~B}$.

Multiple nanoLC-FAIMS-MS/MS and nanoLC-MS/MS experimental parameters were compared. Each experiment consisted of eight separate nanoLC-MS/MS or nanoLC-FAIMS-MS/MS analyses of a $2 \mu \mathrm{g}$ injection of unfractionated yeast tryptic digest. Each nanoLC-FAIMS-MS/MS analysis was performed at a different fixed CV, selected as described below. Precursor MS1 scans over the range of $300-1600 \mathrm{~m} / z$ were collected in the Orbitrap with a nominal resolving power of 120,000 at an $\mathrm{m} / \mathrm{z}$ of 400 . The top 30 precursors were selected for collision-induced dissociation (CID) in the ion trap using data-dependent acquisition (DDA). Monoisotopic precursor selection was enabled, and only doubly- or triply-charged precursors were fragmented. A minimum precursor intensity of 10,000 or 1,000 was required for activation in non-FAIMS and FAIMS experiments, respectively. Dynamic exclusion was employed with an exclusion list of up to 500 precursors. Precursors were excluded with a $\pm 5 \mathrm{ppm}$ tolerance for $45 \mathrm{~s}$ after a single observation or after the precursor level was observed a single time at an intensity below twice the signal-to-noise, whichever came first. The top 30 precursors were isolated with a $2.0 \mathrm{~m} / \mathrm{z}$ window and fragmented by CID for $10 \mathrm{msec}$ at a normalized collision energy of 35 . The total instrument time required for eight analyses, including column re-equilibration between injections, was just under $24 \mathrm{~h}$. The control experiment consisted of eight replicate nanoLC-MS/MS analyses.

The eight CVs expected to yield the most unique peptide identifications for each FAIMS configuration were determined empirically from FAIMS libraries created by performing DDA analyses of the yeast tryptic digest at CVs covering the entire analytically useful range of CVs in $1.0 \mathrm{~V}$ increments (see Supporting Information section 4.A. Empirical Selection of CVs). The CVs selected 
were as follows: for the unmodified FAIMS device with $100 \% \mathrm{~N}_{2}$ carrier gas, $-12.0,-14.0,-16.0,-18.0$, -20.0, -24.0, -28.0, and -32.0 V; for the unmodified FAIMS device with 1:1 He: $\mathrm{N}_{2}$ carrier gas, -22.0, 26.0, -30.0, -33.0, -36.0, -40.0, -46.0, and -56.0V; for the modified FAIMS device with the inner/outer electrodes at $90^{\circ} \mathrm{C} / 70^{\circ} \mathrm{C},-16.0,-18.0,-20.0,-23.0,-26.0,-29.0,-33.0$, and $-41.0 \mathrm{~V}$; and for the modified FAIMS device with the inner/outer electrodes at $70^{\circ} \mathrm{C} / 90^{\circ} \mathrm{C},-18.0,-19.5,-21.0,-22.5,-24.0$, $-25.5,-27.0$, and $-30.0 \mathrm{~V}$.

The experiments comparing FAIMS and OGE were performed using a Proxeon Easy-nLC employing the same LC mobile phases and gradient as above, but separation gradient was performed at $300 \mathrm{~nL} / \mathrm{min}$. Sample was loaded onto the trap with mobile phase $A$ at $6 \mu \mathrm{L} / \mathrm{min}$. The mass spectrometer settings were the same as above except that a precursor range of $400-1600 \mathrm{~m} / \mathrm{z}$ was employed and activation threshold of 1000 counts was employed for all experiments. The reduced-gap FAIMS device was operated with inner and outer electrodes maintained to $70^{\circ} \mathrm{C}$ and $90^{\circ} \mathrm{C}$, respectively. The NSI-FAIMS source was operated with a sheath gas of 3 . The twelve CVs, selected as described above based on a FAIMS map of the yeast sample, were -19.0, -21.0, -22.0, $-23.5,-25.0,-27.0,-29.0,-31.0,-33.0,-35.0,-37.0$, and $-40.0 \mathrm{~V}$.

\section{E. MS1-based gas phase fractionation}

A gas phase fractionation (GPF) method similar to that described by Scherl et al. (8) was also tested. The nanoLC conditions were as described above. The MS conditions were as described above except that for each of the eight nanoLC-MS/MS analyses, the MS1 precursor survey scan was restricted to a different range of $m / z$ values. The eight $m / z$ bins were as follows: $300-484,479$ 596, 591-698, 693-796, 791-895, $890-1000,559-1234$, and 1229-1600. The $m / z$ bins were selected to equally distribute the number of theoretically observable peptide precursors in the yeast proteome. A $5 \mathrm{~m} / \mathrm{z}$ overlap was included to account for edge cases. The distribution of potential peptide $\mathrm{m} / \mathrm{z}$ values was obtained from an in silico digest of the UniRef non-redundant yeast reference proteome (downloaded from www.uniprot.org 2014-03-11), restricting theoretical peptides to those with a peptide length of 7 to 34 residues and a charge of +2 or +3 .

\section{F. Spectrum matching and protein inference}

Mass spectra (.raw files) were converted to mzML format using MSConvert (9) (version 2.2.0) and searched with Comet (10) (version 2013.02 rev. 2). Spectra were searched against the UniRef S. cerevisiae reference proteome in which proteins with $90 \%$ or greater sequence homology were collapsed into a single entry). The protein database was appended to include the following: the 
common Repository of Adventitious Proteins (www.thegpm.org/cRAP, Version 2009.05.1, last updated 18 October 2011) with the Sigma Universal Standard Proteins removed; the common calibration standard peptides human angiotensin I (DRVYIHPFHL) and [Glu-1] fibrinopeptide B (EGVNDNEEGFFSAR); and protein A (GenBank: AAA56730.1). Decoys were generated with Mimic (www.kaell.org), which randomly shuffles the residues between residues cleavable by trypsin. In total, the database contained 6,407 real protein entries and an equal number of decoys. The ratio of decoy to real tryptic peptides was 0.514 . Pertinent Comet parameters were as follows: a wide precursor mass tolerance of $\pm 20 \mathrm{ppm}$ was used to improve the performance of the accurate mass binning tool available in PeptideProphet, and fragment ions were searched with a bin tolerance of 1.0005 and an offset of 0.4. Peptides were assumed to be semi-tryptic with up to 3 missed cleavages allowed. The search parameters included a static modification of $+57.021464 \mathrm{Da}$ at Cys for carbamidomethylation by iodoacetamide and a potential modification of $+15.994915 \mathrm{Da}$ at Met for oxidation. Peptide spectrum matches (PSM) were analyzed using the Trans-Proteomic Pipeline (11) (TPP, version 4.7.0 POLAR VORTEX). PSM probabilities were assigned at the spectrum level by PeptideProphet, and then at the peptide level with iProphet (12). Protein identifications were inferred with ProteinProphet (13). If multiple proteins were inferred at equal confidence by a set of peptides, the inference was counted as a single identification and all relevant protein IDs were listed. Only proteins identified with ProteinProphet probabilities corresponding to a model-estimated false positive error rate (FPER) less than $1.0 \%$ were reported. 


\section{Determining optimal FAIMS carrier gas flow rate}

The residence time of an ion traversing the FAIMS device is a key component of FAIMS separation performance. In planar FAIMS devices without ion focusing, resolving power increases with the square root of residence time while ion transmission efficiency decreases exponentially with residence time (14). Resolving power in cylindrical FAIMS increases slowly with residence time, but there is a species-dependent minimum residence time required to achieve ion focusing $(6,15)$. In the cylindrical FAIMS device described here, residence time is not controlled by the user, but is determined by the rate at which atmosphere is aspirated by the mass analyzer vacuum pumps. Residence time can therefore be estimated as the time required to evacuate the internal volume of the device. The unmodified device has an effective internal volume of $3.0 \mathrm{~mL}$, and has been estimated to have a residence time of $70 \mathrm{~ms}$, corresponding to a flow rate of $2.6 \mathrm{~L} / \mathrm{min}(2-3)$. Estimation of these values is important for two reasons: First, the residence time dictates the length of time that the mass analyzer must pause after the CV changes to allow for equilibrium to be reestablished. The length of this pause introduces loss in duty cycle, and contributes to the fact that internal CV stepping does not improve protein discovery (16) despite improving peak capacity (2). Second, in order to maintain the composition of carrier gas in the FAIMS device, it is necessary to introduce carrier gas at a flow rate greater than it is aspirated by the mass analyzer (17). The excess carrier gas exits the entrance aperture, creating a curtain gas that aids in desolvation when coupling electrospray to FAIMS. This curtain gas has proved problematic for coupling low-flow nanospray to FAIMS, which we have partially addressed by the addition of sheath gas to the nanospray probe (4). Optimizing the carrier gas flow rate is therefore important for maintaining carrier gas composition and obtaining stable spray.

The optimal carrier gas flow rate for the unmodified FAIMS device recommended by the manufacturer is $3.5 \mathrm{~L} / \mathrm{min}$, and this is the most commonly reported value. We evaluated performance of the reduced gap FAIMS device at carrier gas flow rates from 1.0 to $4.0 \mathrm{~L} / \mathrm{min}$ by infusing a mixture of the peptides [Glu-1] fibrinopeptide B and human angiotensin I (Figure S1). The effect of carrier gas flow rate was species-dependent. For the triply-charged angiotensin ion $\left([\mathrm{M}+3 \mathrm{H}]^{3+}=432.9 \mathrm{~m} / \mathrm{z}\right)$, there was a visible shift in FAIMS peak shape and optimal CV of transmission as the carrier gas flow rate increased from $1.0 \mathrm{~L} / \mathrm{min}$ to $2.5 \mathrm{~L} / \mathrm{min}$. The shift in $\mathrm{CV}$ is consistent with a change in carrier gas composition resulting from introduction of lab atmosphere as the carrier gas is introduced at flow rates less than what is aspirated by the mass analyzer's vacuum pumps. Additionally, if the rate at which carrier gas is introduced is exceeded by the vacuum pumps, then there will be no curtain gas exiting the FAIMS entrance aperture. The multiple peaks observed at the lowest carrier gas flow rates 
may be the result of poor declustering and/or poor desolvation of the gas phase ions entering the FAIMS device. The extra peaks collapsed as carrier gas flow rate increased, and peak shape and optimum CV of transmission became stable between 2.0 and $2.5 \mathrm{~L} / \mathrm{min}$, suggesting that flow rate of gas through the FAIMS device is in this range. The void volume of the modified FAIMS with reduced gap was $1.64 \mathrm{~mL}$, corresponding to a residence time of $\sim 40 \mathrm{~ms}$ at $2.5 \mathrm{~L} / \mathrm{min}$. As the carrier gas (and thus the curtain gas) increased further, the optimal $E_{C}$ of transmission did not change, but signal dropped, suggesting that high curtain gas flow rates inhibit efficient transfer of ions from the nanospray source into the FAIMS device. Contrasting the behavior of the angiotensin ion, FAIMS peak shape and optimal CV of transmission did not significantly change for the doubly-charged [Glu-1] fibrinopeptide B ion $\left([\mathrm{M}+2 \mathrm{H}]^{2+}=785.8 \mathrm{~m} / \mathrm{z}\right)$. The ion transmission efficiency was greatest at a carrier gas flow rate of $1.0 \mathrm{~L} / \mathrm{min}$, and decreased as carrier gas flow rate increased, supporting the hypothesis that curtain gas affects ion transfer from ion source to the FAIMS device. Based on these results, we used carrier gas flow rates of $2.5 \mathrm{~L} / \mathrm{min}$ for subsequent nanoLC-FAIMS-MS/MS experiments with the modified electrodes.
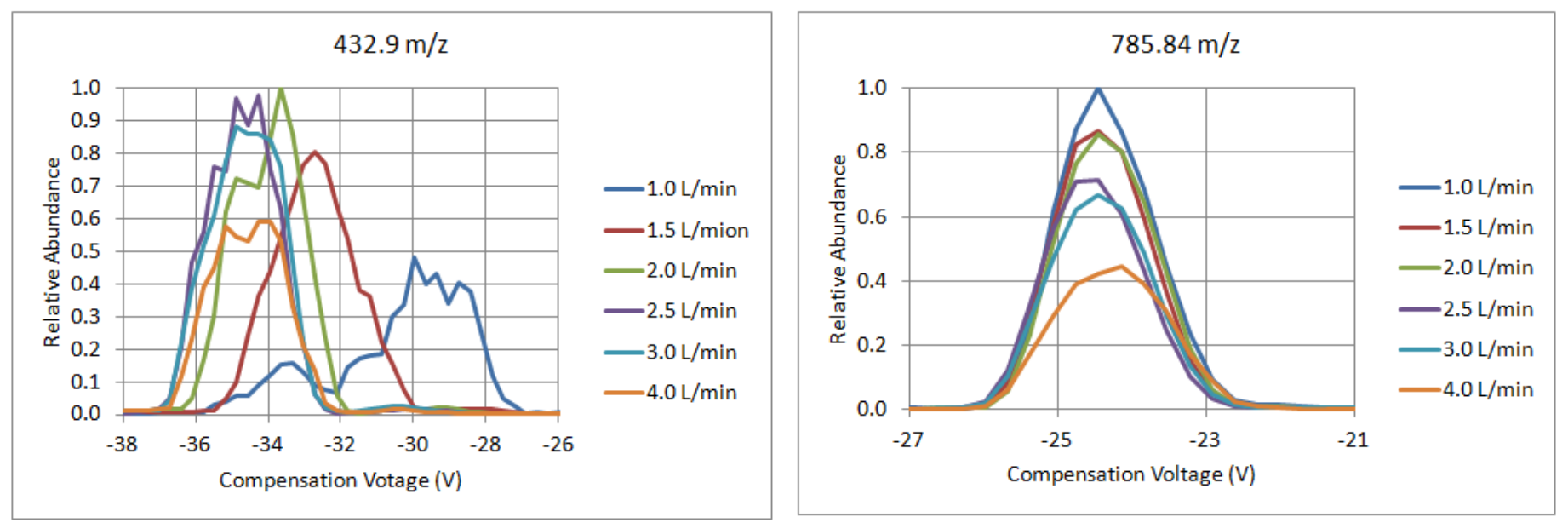

Figure S1. Determining optimal FAIMS carrier gas flow rate. A mixture of human angiotensin I $\left([\mathrm{M}+3 \mathrm{H}]^{3+}=432.9 \mathrm{~m} / \mathrm{z}\right)$ and [Glu-1] fibrinopeptide $\left([\mathrm{M}+2 \mathrm{H}]^{2+}=785.8 \mathrm{~m} / \mathrm{z}\right)$ was infused and analyzed by nanospray-FAIMS-MS using a cylindrical FAIMS device modified to have a narrow gap of $1.25 \mathrm{~mm}$ (dispersion field $-32 \mathrm{kV} / \mathrm{cm}$ ). The inner and outer electrodes were maintained at $70^{\circ} \mathrm{C}$ and $90^{\circ} \mathrm{C}$, respectively. The $\mathrm{N}_{2}$ carrier gas was introduced at flow rates from 1.0 to $4.0 \mathrm{~L} / \mathrm{min}$. The effect of flow rate on FAIMS peak shape and ion transmission efficiency was species-dependent. A flow rate of $2.5 \mathrm{~L} / \mathrm{min}$ was selected for subsequent nanoLC-FAIMS-MS/MS experiments. 


\section{Programmed FAIMS dwell time is not necessary due to instrumental latency.}

FAIMS dwell time, an instrumental parameter that is set in the instrument configuration controls, is a programmed delay in data acquisition after switching CVs. This programmed delay is intended to provide adequate time for the analyte ion stream to reach equilibrium under the new CV conditions. As discussed in Supporting Information section 2. Determining optimal FAIMS carrier gas flow rate, the estimated residence time for the unmodified FAIMS device is $\sim 70 \mathrm{msec}$, so the logical setting for FAIMS dwell time would be a value $70 \mathrm{msec}$ or greater. However, we observed that the instrument exhibits a baseline latency in excess of $120 \mathrm{msec}$ when switching between CVs; that is, when the CV is switched, it takes the instrument at least $120 \mathrm{msec}$ to acquire new spectra, and any programmed CV dwell time only adds additional wait time. Evidence for this pause is shown in Figure S2. A mixture of caffeine $\left([\mathrm{M}+1 \mathrm{H}]^{1+}=195.1 \mathrm{~m} / \mathrm{z}\right)$ and human angiotensin I (DRVYIHPFHL, $[\mathrm{M}+3 \mathrm{H}]^{3+}=432.9 \mathrm{~m} / \mathrm{z}$ ) was infused and analyzed by NSI-FAIMS-MS on an LTQ Velos Orbitrap. Precursor spectra were collected in the LTQ using Turbo scan mode. The automatic gain control was set to acquire $3 \times 10^{4}$ ions per scan while the trap fill time was restricted to $0.1 \mathrm{msec}$, much less time than was required to achieve the programmed ion volume. These settings ensured that each scan was equal in duration. Data were acquired either at a fixed CV or alternating between two different CVs (that is, the CV switched after each scan). For both experiment types, the FAIMS dwell time was set at $150 \mathrm{msec}, 100 \mathrm{msec}, 50 \mathrm{msec}$, or $1 \mathrm{msec}$ (the minimum allowable setting). Spectra were acquired for two min at each setting and the average time required to acquire a single spectrum was calculated. As would be expected, programmed FAIMS dwell time had no effect on the acquisition rate when the $\mathrm{CV}$ was fixed for the duration of the experiment. The average elapsed time between consecutive scans was $104 \mathrm{msec}$. When the CV was changed prior to acquiring each spectrum, the average elapsed time between spectra increased in direct proportion to the programmed FAIMS dwell time delay (Figure S2). The $y$-intercept of the curve fit to these data provided an estimate of the average scan acquisition time without a programmed FAIMS dwell time delay. This value was $229 \mathrm{msec}$, corresponding to an instrumental latency of $125 \mathrm{msec}$ when switching between CVs. Setting the FAIMS dwell time delay to the minimum allowable $1 \mathrm{msec}$ had no discernable effect on FAIMS separation, suggesting that the unprogrammed instrumental delay was sufficient time for the FAIMS device to change CVs and for the analyte ion stream to come to equilibrium under the new conditions. 

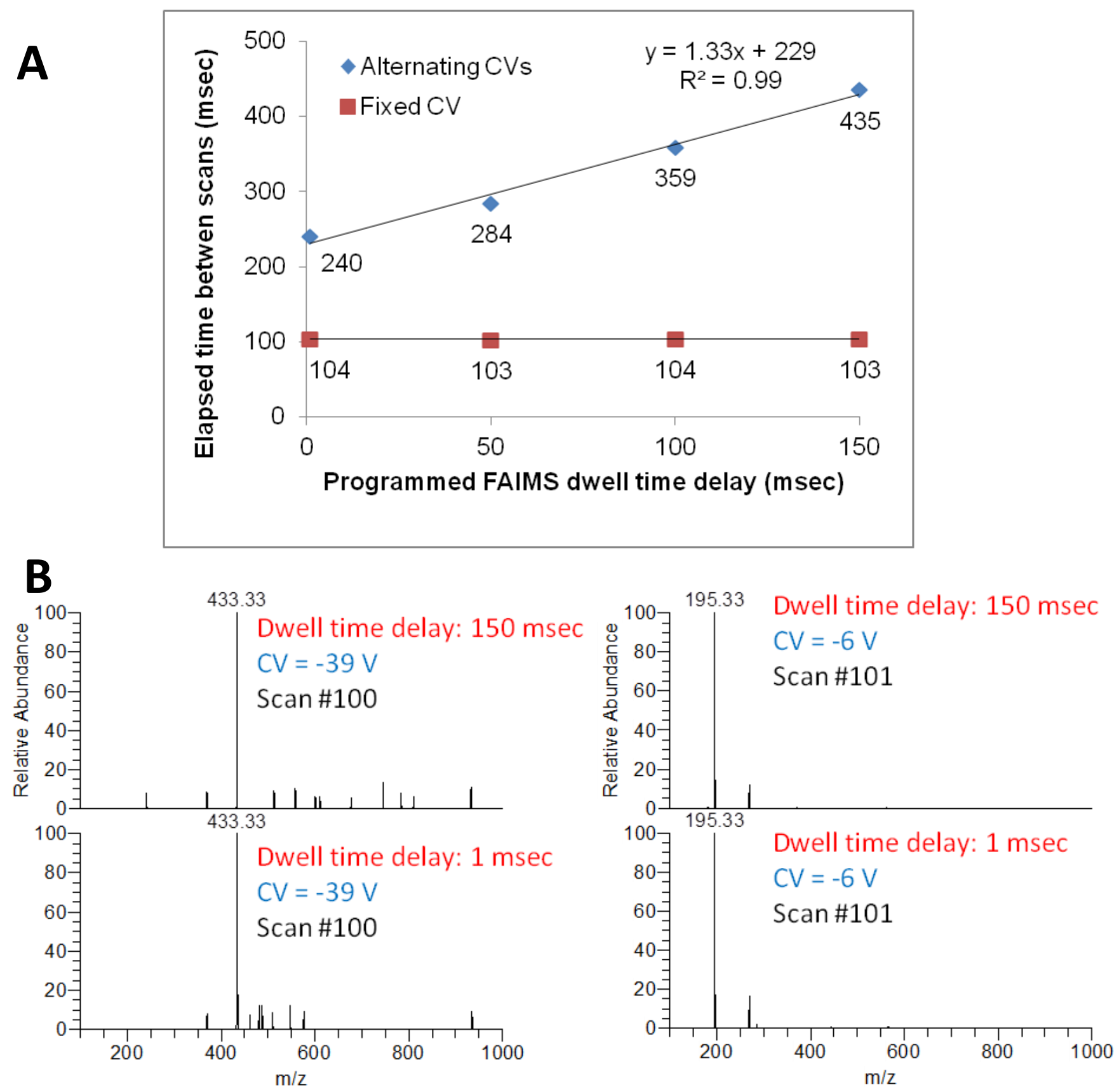

Figure S2. Instrumental latency in CV switching. A programmed FAIMS dwell time delay inserts a pause of pre-determined duration before acquiring new spectra after switching CVs. This pause is ostensibly to allow the analyte ion stream to come to equilibrium within the FAIMS device after switching CVs, which is estimated to require approximately $70 \mathrm{msec}$. A mixture of caffeine $\left([\mathrm{M}+1 \mathrm{H}]^{+}=\right.$ $195.33 \mathrm{~m} / \mathrm{z})$ and human angiotensin I $\left([\mathrm{M}+3 \mathrm{H}]^{3+}=432.9 \mathrm{~m} / \mathrm{z}\right)$ was infused and analyzed by NSIFAIMS-MS. The CV was alternated every scan with various programmed FAIMS dwell time delays. There was observed to be additional latency when switching between CVs that was not due to the programmed FAIMS dwell time delay (A). This instrumental latency resulted in a delay of approximately $125 \mathrm{msec}$ before acquiring spectra after switching CVs, which was more than sufficient time for the analyte ion stream to reach equilibrium, as evidenced by complete separation of the two compounds (B). Subsequent scans acquired at different CVs with a programmed FAIMS dwell time delay of $150 \mathrm{msec}$ (TOP) or $1 \mathrm{msec}$ (BOTTOM) showed that, in practice, the FAIMS dwell time can be programmed to the minimum allowable $1 \mathrm{msec}$ with no loss of FAIMS performance. 


\section{FAIMS Libraries}

\section{A. Empirical Selection of CVs.}

The eight CVs expected to yield the most unique peptide identifications for each FAIMS configuration were determined empirically from FAIMS libraries created by performing DDA analyses of the yeast tryptic digest at CVs covering the entire analytically useful range of CVs in $1.0 \mathrm{~V}$ increments. In order to reduce the instrumental time required to generate these libraries, the nanoLCFAIMS-MS/MS analyses for creating the FAIMS libraries were performed in a CV-stepping fashion: a precursor MS1 scan and the MS2 scans of the selected precursors were performed at one CV, and the next set of MS1 and related MS2 scans were performed at a different CV. Each nanoLC-FAIMSMS/MS analysis continuously stepped through $3 \mathrm{CVs}$ for the duration of the data acquisition. Internal CV stepping does not provide as deep of proteome coverage as holding a fixed CV for each nanoLCFAIMS-MS/MS analysis due to the loss in duty cycle (16) (Table S1), but the approach enabled characterization of peptide behavior in the various FAIMS devices. The nanoLC conditions were as described in the methods section of the manuscript. The MS conditions were as described except as follows: in order to fully characterize the sample, the MS1 precursor scans were collected over 300-1800 m/z and all precursor charge states were allowed; in order to account for FAIMS fractionation, dynamic exclusion was enabled with a $\pm 10 \mathrm{ppm}$ tolerance after a precursor had been observed three times rather than one time; and early removal of low-abundance precursors from the exclusion list was disabled. The FAIMS conditions for each configuration were as described, except that the carrier gas was supplied at $3.0 \mathrm{~L} / \mathrm{min}$ for the modified FAIMS, and nanospray source sheath gas was set at 1 arbitrary unit for the unmodified FAIMS. (Subsequent experimentation showed that increasing the sheath gas to 5 units provided better signal and spray stability with the unmodified FAIMS device, and this value was used for the final protein discovery experiments). Plots of optimal $E_{C}$ of ion transmission with respect to $\mathrm{m} / \mathrm{z}$ were generated using peptides identified with iProphet probabilities corresponding to false positive error rates below $0.1 \%$. The optimal $E_{C}$ of transmission of each peptide ion was estimated as the $E_{C}$ corresponding to the maximum signal of an extracted ion FAIMS spectrum (precursor ion intensity with respect to $E_{C}$ ) generated by matching the peptide to precursor spectra with a $10 \mathrm{ppm}$ mass tolerance and a $120 \mathrm{~s}$ retention time tolerance.

As no tool yet exists for predicting the optimal $E_{C}$ of transmission for a peptide based on its sequence, the CVs for each nanoLC-FAIMS-MS/MS experiment were determined empirically from the FAIMS libraries generated for each condition. We designed a computer algorithm to select the optimum CVs for a given number of nanoLC-FAIMS-MS/MS analyses to be undertaken. The algorithm was provided a list of the unique peptide sequences identified at each CV. The CV that 
contributed the least number of novel peptides was removed in an iterative fashion until only the specified number of CVs remained. Each selected CV was then sequentially substituted with its nearest neighbor $\mathrm{CV}$ to determine if the total number of identified peptides could be increased by fine tuning.

In addition to enabling empirical selection of optimal CVs for protein discovery experiments, the FAIMS libraries enabled observation of general trends in the behavior of peptides in FAIMS (Figure S3). First, singly-charged peptides are observed at the lowest magnitude $E_{C}$ (or, for this FAIMS device, the most positive CV values). This characteristic of FAIMS allows exclusion of the large majority of singly-charged precursors. Second, the non-uniform distribution of peptides across the range of $E_{C}$ demonstrates the importance of informed selection of $E_{C}$ for FAIMS fractionation. The spacing of $E_{C}$ is dependent both on the density of peptides and the width of the FAIMS peak at a given range of $E_{C}$. Finally, it can be seen that even with eight optimally-selected $E_{C}$, not all peptides in a given sample will be analyzed. This is a crucial difference between FAIMS fractionation and other fractionation techniques such as strong cation exchange or isoelectric focusing. Comparing the libraries of the selectivity-optimized and sensitivity-optimized modified FAIMS, it can be seen that increasingly narrow FAIMS peaks result in a smaller region of FAIMS analytical space being sampled. However, the results presented here demonstrate that increased FAIMS resolving power is preferable for shotgun proteomics despite undersampling of the ion population from a finite number of nanoLC-MS injections. 
Table S1. Protein discovery by extensive FAIMS fractionation. The top table is expanded from Table 2 in the main text. The bottom table shows protein and peptide discovery from the data used to generate the FAIMS libraries that were used to empirically select the best $8 \mathrm{CVs}$ for analysis. Despite many more injections covering the entire useful range of compensation voltages for each FAIMS configuration, fewer proteins were identified from these experiments, likely due to the loss of duty cycle from intra-run CV stepping.

\begin{tabular}{|c|c|c|c|c|c|c|c|c|c|c|c|c|c|c|}
\hline $\begin{array}{l}\text { Gas-phase } \\
\text { Fractionation } \\
\text { Technique }\end{array}$ & $\begin{array}{l}\text { Electrode } \\
\text { gap }\end{array}$ & $\begin{array}{c}\text { Carrier } \\
\text { gas }\end{array}$ & $\begin{array}{l}\text { Electrode } \\
\text { Temperature } \\
\text { Inner/Outer }\end{array}$ & $\begin{array}{c}\text { Dispersion } \\
\text { Field }\end{array}$ & $\begin{array}{c}\text { Total } \\
\text { LC-MS } \\
\text { runs }\end{array}$ & $\begin{array}{l}\text { Total } \\
\text { CVs }\end{array}$ & $\begin{array}{l}\text { CVs/ } \\
\text { LC-MS } \\
\text { run }\end{array}$ & CVs & $\begin{array}{c}\text { Proteins } \\
\text { (FPER < } \\
1.0 \%)\end{array}$ & $\begin{array}{c}\% \text { Single } \\
\text { Hit } \\
\text { Proteins }\end{array}$ & $\begin{array}{c}\text { Peptide } \\
\text { Spectrum } \\
\text { Matches } \\
(\text { FPER }<1.0 \%)\end{array}$ & $\begin{array}{c}\text { Peptides } \\
(\text { FPER }<1.0 \%)\end{array}$ & $\begin{array}{l}\text { Peptides/ } \\
\text { Protein }\end{array}$ & $\begin{array}{l}\text { Spectra/ } \\
\text { Peptide }\end{array}$ \\
\hline $\begin{array}{l}\text { Modified } \\
\text { FAIMS }\end{array}$ & $1.25 \mathrm{~mm}$ & $\mathrm{~N}_{2}$ & $70^{\circ} / 90^{\circ}$ & $-32 \mathrm{kV} / \mathrm{cm}$ & 8 & 8 & 1 & $\begin{array}{c}-18,-19.5,-21,-22.5 \\
-24,-25.5,-27,-30\end{array}$ & 3,163 & $14.3 \%$ & 60,790 & 29,862 & 9.4 & 2.0 \\
\hline $\begin{array}{l}\text { Modified } \\
\text { FAIMS }\end{array}$ & $1.25 \mathrm{~mm}$ & $\mathrm{~N}_{2}$ & $90^{\circ} / 70^{\circ}$ & $-32 \mathrm{kV} / \mathrm{cm}$ & 8 & 8 & 1 & $\begin{array}{c}-16,-18,-20,-23,-26, \\
-29,-33,-41\end{array}$ & 2,697 & $14.9 \%$ & 68,082 & 26,815 & 9.9 & 2.5 \\
\hline $\begin{array}{l}\text { Unmodified } \\
\text { FAIMS }\end{array}$ & $2.5 \mathrm{~mm}$ & $\begin{array}{c}1: 1 \\
\mathrm{He}: \mathrm{N}_{2}\end{array}$ & $70^{\circ} / 90^{\circ}$ & $-20 \mathrm{kV} / \mathrm{cm}$ & 8 & 8 & 1 & $\begin{array}{c}-22,-26,-30,-33,-36 \\
-40,-46,-56\end{array}$ & 2,072 & $14.3 \%$ & 71,356 & 20,236 & 9.8 & 3.5 \\
\hline $\begin{array}{l}\text { Unmodified } \\
\text { FAIMS }\end{array}$ & $2.5 \mathrm{~mm}$ & $\mathrm{~N}_{2}$ & $70^{\circ} / 90^{\circ}$ & $-20 \mathrm{kV} / \mathrm{cm}$ & 8 & 8 & 1 & $\begin{array}{c}-12,-14,-16,-18,-20 \\
-24,-28,-32\end{array}$ & 1,707 & $15.4 \%$ & 71,908 & 16,739 & 9.8 & 4.3 \\
\hline MS1 & - & - & - & - & 8 & - & - & - & 1,696 & $20.6 \%$ & 29,420 & 11,975 & 7.1 & 2.5 \\
\hline $\begin{array}{c}\text { No } \\
\text { fractionation }\end{array}$ & - & - & - & - & 8 & - & - & - & 1,597 & $19.7 \%$ & 131,346 & 14,051 & 8.8 & 9.3 \\
\hline
\end{tabular}

\begin{tabular}{|c|c|c|c|c|c|c|c|c|c|c|c|c|c|c|}
\hline $\begin{array}{l}\text { Modified } \\
\text { FAIMS }\end{array}$ & $1.25 \mathrm{~mm}$ & $\mathrm{~N}_{2}$ & $70^{\circ} / 90^{\circ}$ & $-32 \mathrm{kV} / \mathrm{cm}$ & 25 & 68 & 3 & $-5,-6,-7, \ldots-79$ & 2,785 & $14.2 \%$ & 195,258 & 33,419 & 12.0 & 5.8 \\
\hline $\begin{array}{l}\text { Modified } \\
\text { FAIMS }\end{array}$ & $1.25 \mathrm{~mm}$ & $\mathrm{~N}_{2}$ & $90^{\circ} / 70^{\circ}$ & $-32 \mathrm{kV} / \mathrm{cm}$ & 18 & 54 & 3 & $-5,-6,-7, \ldots-58$ & 2,197 & $18.7 \%$ & 187,626 & 23,446 & 10.7 & 8.0 \\
\hline $\begin{array}{l}\text { Unmodified } \\
\text { FAIMS }\end{array}$ & $2.5 \mathrm{~mm}$ & $\begin{array}{c}1: 1 \\
\mathrm{He}: \mathrm{N}_{2}\end{array}$ & $70^{\circ} / 90^{\circ}$ & $-20 \mathrm{kV} / \mathrm{cm}$ & 13 & 39 & 3 & $-4,-3,-2, \ldots-80$ & 1,321 & $21.3 \%$ & 119,247 & 10,856 & 8.2 & 11.0 \\
\hline $\begin{array}{c}\text { Unmodified } \\
\text { FAIMS }\end{array}$ & $2.5 \mathrm{~mm}$ & $\mathrm{~N}_{2}$ & $70^{\circ} / 90^{\circ}$ & $-20 \mathrm{kV} / \mathrm{cm}$ & 10 & 30 & 3 & $8,7,6, \ldots-50$ & 1,063 & $23.7 \%$ & 82,250 & 7,861 & 7.4 & 10.5 \\
\hline
\end{tabular}



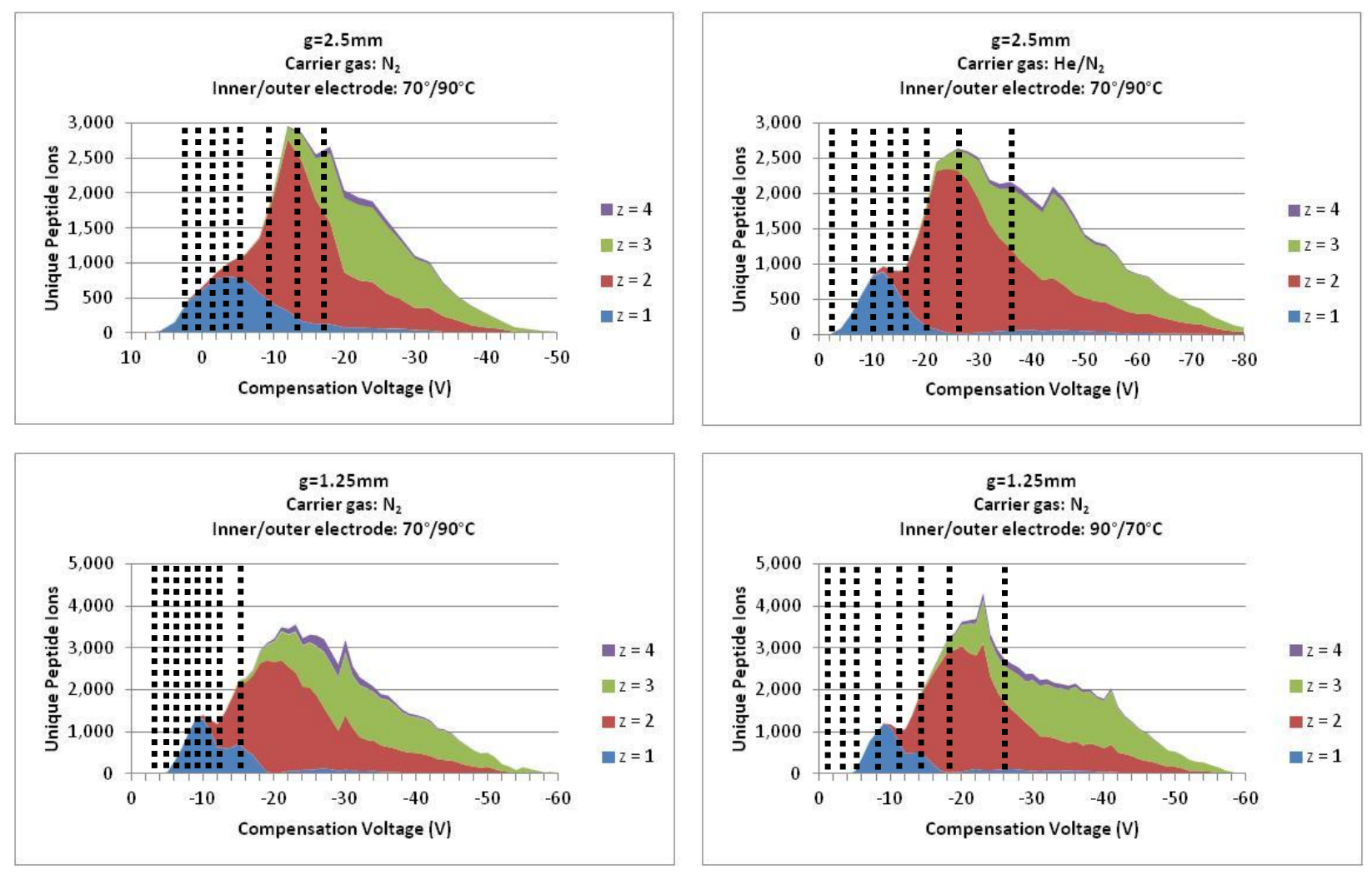

Figure S3. Empirical selection of compensation voltages. An unfractionated yeast tryptic digest was analyzed by nanoLC-FAIMS-MS/MS using four different FAIMS device configurations. Narrowlyspaced compensation voltages spanning the entire FAIMS separation window were employed in order to empirically determine the best voltages to select for future experiments. The number of unique peptide ions (peptides with unique sequence and charge) identified at each compensation voltage are shown. The plot area is color coded to show the proportion of ion charge states at each voltage. The eight compensation voltages selected to compare FAIMS-aided protein discovery in a $24 \mathrm{~h}$ experiment are shown as dashed vertical lines. These eight voltages yielded the greatest number of unique peptide sequences from the doubly- and triply-charged peptide ions. 


\section{B. Behavior of Peptides in FAIMS}

The mechanisms that govern the behavior of peptides in FAIMS are poorly understood, and at present it is not possible to predict the optimal $E_{C}$ of transmission for a peptide based on its sequence alone. The FAIMS libraries described here for the optimization of $E_{C}$ selection facilitate some generalizations about FAIMS separation of peptides. Figure $S 4$ shows the $E_{C}$ of maximum transmission with respect to mass-to-charge for nearly 39,000 unique peptide ions (peptides with unique sequence and charge) identified using the modified FAIMS device optimized for peak capacity (inner electrode cooler than outer electrode). Peptide ions with the largest $m / z$ are generally observed over a narrow range of low magnitude $E_{C}$. As $m / z$ decreases, the $E_{C}$ at which peptides are observed increases, as does the range of $E_{C}$. The general behavior of peptides is different for different charge states. Singly-charged peptides exhibit the smallest average $E_{C}$ for a given $\mathrm{m} / z$. The optimal $E_{C}$ for multiply-charged peptides has low overlap with those of singly-charged peptides. This separation is most dramatic at the largest $\mathrm{m} / \mathrm{z}$, where there is complete separation of singly-charged, doublycharged, and triply-charged peptides. The difference between $E_{C}$ ranges for doubly-charged and triply-charged peptides is much less pronounced, though there is still significant enrichment for doubly-charged peptides at lower $E_{C}$ and for triply-charged peptides at higher $E_{C}$. Relatively few peptides with $z>4$ were observed, but these suggest that the range of optimal $E_{C}$ for highly-charged peptides largely overlaps that of triply-charged peptides, and we have confirmed this with other studies of longer, more highly-charged LysC-digested peptides (data not shown).

When the plots of $E_{C}$ vs. $m / z$ are considered separately for each charge state, peptides can be seen to form distinct clusters in $E_{C}$ vs. $\mathrm{m} / z$ space (Figure S4). Peptide ions with charge states of +3 and higher appear to form single, irregularly-shaped clusters, but at lower charge states it becomes apparent that there are multiple populations of ions exhibiting distinct behaviors within a given charge state. This is most apparent with singly-charged peptides, for which at least three sub-populations can be clearly distinguished. The large majority of peptide ions (89\%) are observed with $\left|E_{C}\right|$ below $150 \mathrm{~V} / \mathrm{cm}$. (It is possible that at $\mathrm{m} / \mathrm{z}$ below 600 , the population of singly-charged peptides would spread to larger $E_{C}$ in a fashion similar to the populations of more highly charged peptides. However, the peptide spectrum matching search parameters used here do not consider peptides with less than 7 residues; consequently, no singly-charged peptides were identified with $m / z$ less than $\sim 600$. 

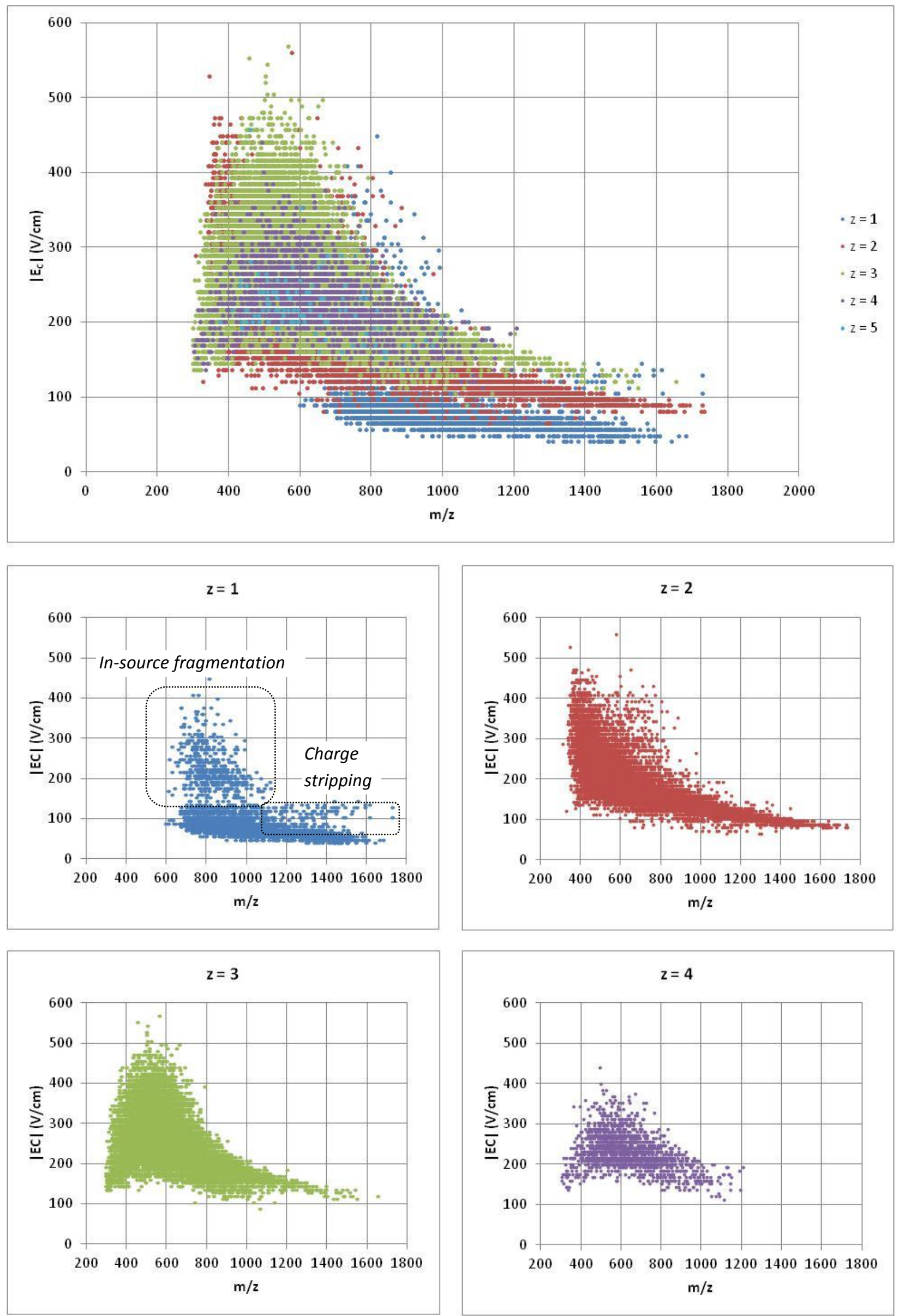

Page S-19 
Figure S4. Separation of peptides in FAIMS. The optimal compensation voltage of transmission (given as the magnitude of the compensation field $E_{C}$ ) is plotted with respect to peptide mass-tocharge for nearly 39,000 unique peptide ions identified by nanoLC-FAIMS-MS/MS of an unfractionated yeast tryptic digest. These plots were generated with a cylindrical FAIMS device modified to have a narrow electrode gap of $1.25 \mathrm{~mm}$ (dispersion field $=32 \mathrm{kV} / \mathrm{cm}$ ). The electrode temperatures were set to optimize peak capacity (inner and outer electrodes at $70^{\circ} \mathrm{C}$ and $90^{\circ} \mathrm{C}$, respectively). Carrier gas was pure $\mathrm{N}_{2}$. Peptide ions of different charge states can be seen to cluster in different regions. Singly-charged species hypothesized to be generated by charge stripping and post-FAIMS in-source fragmentation are indicated. 


\section{C. FAIMS provides evidence of in-source fragmentation and charge stripping}

Shotgun proteomics experiments typically identify peptides exhibiting protein cleavage that is not consistent with the enzyme used for proteolytic digest. It has been shown that a significant proportion of these peptides with non-specific cleavage arise from so-called "in-source fragmentation" of peptide ions (18). A FAIMS study of metabolites showed that the bulk of this fragmentation occurs after the mass analyzer orifice (and thus after the FAIMS device) (19). The FAIMS libraries described here show further evidence that fragmentation as well as charge reduction of peptide ions occurs after the ions enter the mass analyzer. A group of singly-charged peptide ions can be seen to be wellseparated from other singly-charged ions in $E_{C}$ vs. $\mathrm{m} / \mathrm{z}$ space, occupying a region of higher $\left|E_{C}\right|$ which is populated primarily with higher charge state ions (Figure S4). Evidence suggests that these peptides were separated by FAIMS as higher mass peptides and then fragmented into smaller, lowercharged peptides prior to detection by the mass analyzer. This hypothesis is supported by the fact that only $2.2 \%$ of singly-charged peptides identified with $\left|E_{C}\right|>150 \mathrm{~V} / \mathrm{cm}$ exhibited two tryptic termini, whereas $76 \%$ of peptides in the main population with $\left|E_{C}\right|<150 \mathrm{~V} / \mathrm{cm}$ were fully tryptic. (For comparison, $75 \%$ of all peptides identified without FAIMS were fully tryptic.) Furthermore, for the majority of these semi-tryptic fragments, a longer peptide containing the fragment was identified with a higher charge state at or near the same $E_{C}$. An example of such a peptide is given in Figure S5. A third population of singly-charged peptides with $\mathrm{m} / z>\sim 1000$ and $\left|E_{C}\right|$ between 100 and $150 \mathrm{~V} / \mathrm{cm}$ are cleanly separated in $E_{C}$ space from the majority of singly-charged peptides of the same $\mathrm{m} / \mathrm{z}$. Manual examination of these peptides showed that they are actually separated by FAIMS at a higher charge state but then undergo charge stripping prior to detection by the mass analyzer. Evidence for post-FAIMS, in-source charge stripping of a peptide ion is shown in Figure S5. 


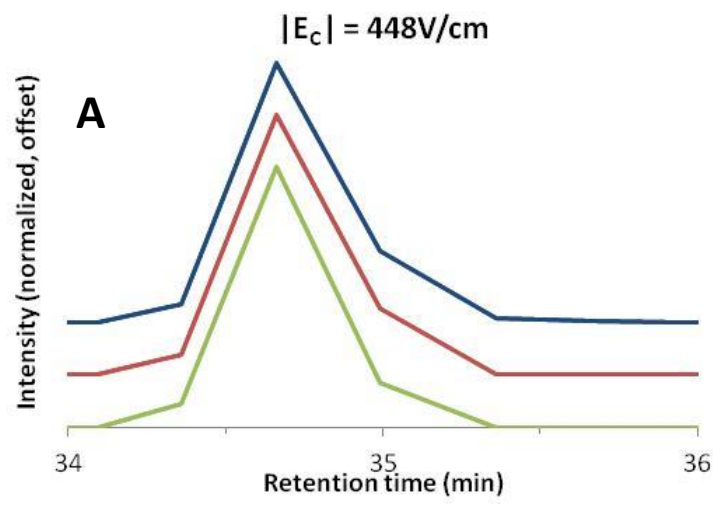

Retention time $=\mathbf{3 4 . 7} \mathrm{min}$

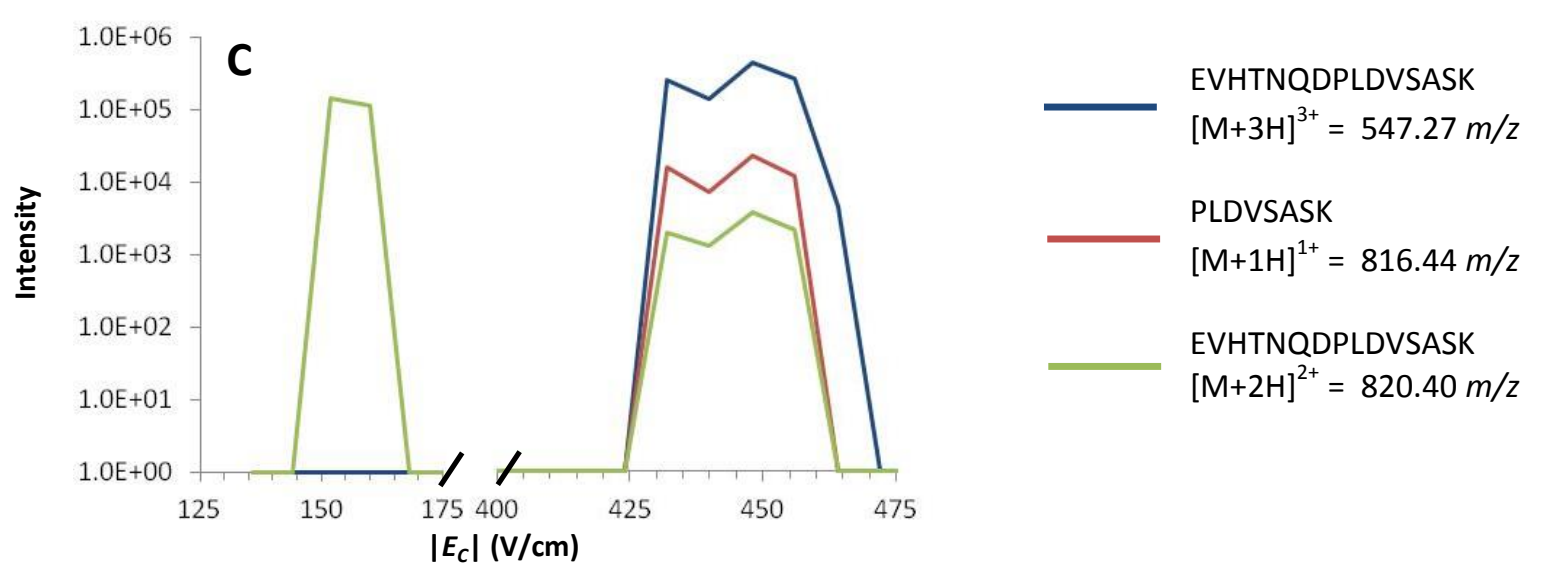

Figure S5. FAIMS reveals charge stripping and in-source fragmentation. Peptides may undergo in-source fragmentation and charge-stripping after FAIMS separation. This example was obtained from nanoLC-FAIMS-MS/MS analyses of an unfractionated yeast tryptic digest performed across a range of compensation voltages (reported here as the magnitude of the compensation field $\left|E_{C}\right|$ in $\mathrm{V} / \mathrm{cm}$ ). The peptide EVHTNQDPLDVASK was confidently identified in both the doubly-charged $(820.40 \mathrm{~m} / \mathrm{z})$ and triply-charged forms $(547.27 \mathrm{~m} / \mathrm{z})$. The peptide eluted as a single species $(A)$ and the doubly- and triply-charged species were separated by FAIMS (C). A singly-charged fragment of the peptide, PLDVSASK, was also confidently identified. This peptide fragment perfectly co-eluted with the intact peptide (A) and exhibited a FAIMS profile identical to the triply-charged peptide (B), despite the fact that the large majority of singly-charged peptides exhibit much smaller $E_{C}$ values (see Figures S3 and S4). It is highly likely that the peptide fragment arose from in-source fragmentation of the longer peptide after FAIMS separation. While the doubly-charged ion was confidently identified with an optimal $E_{C}$ of transmission at $152 \mathrm{~V} / \mathrm{cm}$, an ion with identical $\mathrm{m} / \mathrm{z}$ (mass difference $<1 \mathrm{ppm}$ ) was also observed to exhibit an identical FAIMS profile as the triply-charged ion $(B, C)$. This species likely arose from a small portion of the population of triply-charged peptide ions undergoing charge-stripping after FAIMS separation but prior to detection. 


\section{Theoretically-predicted effects of changes to electrode shape and temperature}

The modifications described here were expected to have significant impact on both FAIMS separation and the efficiency of ion transfer through the FAIMS device due to their impact on ion focusing, a phenomenon that arises in FAIMS devices with curved electrodes (20). The inhomogeneous fields within these devices cause the otherwise disperse ion cloud to focus into a narrow band between the electrodes (21). Ion focusing increases ion transmission efficiency by counteracting diffusion, while at the same time decreasing FAIMS resolving power by causing species that would otherwise have separated at a given $E_{C}$ to come into equilibrium between the electrodes. Increased ion focusing can be observed as an increase in the width of FAIMS peaks (signal with respect to $\left.E_{C}\right)(6,20)$.

\section{A. Effect of decreased gap width}

Increasing the strength of $E_{D}$ by decreasing the electrode gap was expected to increase the effect of atmospheric pressure ion focusing (20). However, increasing the radius of the inner electrode as described here was also expected to decrease the effect of ion focusing by decreasing the difference in field strength between the inner and outer electrode (3). The field strength at a given point in a cylindrical FAIMS device can be calculated as

$$
E(r)=\frac{-V_{a}}{r \ln (a / b)}
$$

where $E$ is the electric field strength at a radial distance $r$ from the center of the inner electrode, $V$ is the voltage applied to the inner electrode, $a$ is the outer radius of the inner electrode, and $b$ is the inner radius of the outer electrode (20). If there is no temperature gradient introduced that will affect the gas number density (1), then the ratio of field strengths at the inner electrode and outer electrodes, respectively, is equal to the ratio of the outer and inner radii, respectively; that is,

$$
\frac{E_{a}}{E_{b}}=\frac{b}{a}
$$

The dimensions of the unmodified FAIMS device correspond to $E$ being 1.38 times greater at the inner electrode than at the outer electrode, whereas $E$ would be only 1.16 times greater at the inner electrode if the electrode gap is narrowed as described here. This decrease in field strength gradient should decrease the effects of ion focusing, leading to narrower FAIMS peaks and poorer ion transmission efficiency. 


\section{B. Effect of electrode temperature}

The performance of the modified FAIMS device was further modulated by altering the electrode temperatures. The effect of field strength on an ion's mobility is a function not only of the electric field $E$, but also of the gas number density $N(22)$. Increasing temperature decreases the density of gas molecules in the FAIMS carrier gas, increasing ion mobilities at a given field strength. Two temperature configurations were tested with the modified FAIMS device: maintaining the inner and outer electrodes at $70^{\circ} \mathrm{C}$ and $90^{\circ} \mathrm{C}$, respectively; and the inverse. Setting the inner electrode cooler than the outer electrode establishes a temperature gradient, and thus a gas density gradient, that should decrease ion mobilities with respect to field strength at the inner electrode relative to the outer electrode. Since the predicted effect of this temperature scheme is in direct opposition to predicted effect of the increased field strength at the inner electrode relative to the outer electrode, a cooler inner electrode relative to outer electrode was expected to reduce the effect of ion focusing and lead to narrower FAIMS peaks at the cost of ion transmission efficiency. Conversely, setting the inner electrode warmer than the outer electrode should increase ion mobilities at the inner electrode relative to the outer electrode, augmenting the field gradient created by the curved electrode geometry. This temperature scheme was expected to increase ion focusing, and thus ion transmission efficiency, while concomitantly increasing FAIMS peak widths.

\section{C. The relationship between FAIMS peak width and ion focusing}

The observed relationship between FAIMS peak width (measured as the peak width at half maximum, $w)$ and $E_{C}$ varied widely among the four electrode configurations tested. In the absence of ion focusing, as in FAIMS devices with parallel planar electrodes, FAIMS peak width is a function of the individual ion's mobility and is independent of $E_{C}(23)$. In FAIMS devices with curved electrode geometries, FAIMS peaks broaden with increasing $E_{C}$ due to increased ion focusing for ions with greater field dependence of ion mobility $(6,20,24)$. Studies with polyethylene glycol (5) showed a quasi-linear relationship between FAIMS peak width and $E_{C}$. We observed weak correlation between $w$ and $E_{C}$ with the unmodified electrode employing $\mathrm{N}_{2}$ carrier gas (Figure S6A). Peak widths generally increased at larger $E_{C}$, but the plot of $w$ vs. $E_{C}$ was essentially flat at low $E_{C}$. The low dependence of $w$ on $E_{C}$ suggests minimized ion focusing, which is consistent with the low $E_{C}$ magnitudes observed in this configuration compared to the others, and the fact that holding the outer electrode warmer than the inner electrode establishes a temperature gradient that counteracts the field gradient established by the electrode geometries(1). Consistent with theory and previous reports (25-28), adding He to the carrier gas while keeping all else the same significantly increased field dependence of ion mobilities, 
as evidenced by increased $E_{C}$ magnitudes. Suppression of ion focusing was overcome and a very strong correlation between $w$ and $E_{C}$ was established (Figure $\mathrm{S} 6 \mathrm{~B}$ ). The shift in $E_{C}$ magnitude upon addition of He was not uniform, but rather directly proportional to $E_{C}$ magnitude; a plot of $E_{C}$ with 1:1 $\mathrm{N}_{2}$ : He versus $E_{C}$ with $\mathrm{N}_{2}$ only was linear $\left(R^{2}=0.92\right)$ with a slope of 2.23. Because the increase in the FAIMS separation window was greater than the concomitant increase in FAIMS peak width, FAIMS peak capacity increased $69 \%$ from 3.8 to 6.5 .

Contrasting the effect of adding $\mathrm{He}$ to the carrier gas, narrowing the electrode gap while employing $\mathrm{N}_{2}$ as the carrier gas and maintaining an electrode temperature gradient (inner electrode cooler than outer electrode) in opposition to the electric field gradient greatly reduced dependence of $w$ on $E_{C}$ (Figure $\mathrm{S6C}$ ). $E_{C}$ magnitudes increased significantly as a result of the increased dispersion field strength, but peak widths were narrower due to decreased ion focusing resulting from reduced electrode curvature (3). The expansion of $E_{C}$ range combined with narrowing peaks increased peak capacity over six-fold to 24.7. Reversing the temperature gradient on the reduced gap device such that the inner electrode was warmer than the outer electrode enhanced rather than counteracted ion focusing (1), restoring some $E_{C}$ dependence of $w$ (Figure S6D). Increased ion focusing decreased peak capacity to 8.4 , which was still over 2-fold greater than with the unmodified electrode with $\mathrm{N}_{2}$ carrier gas and $30 \%$ greater than with the unmodified electrode with $\mathrm{N}_{2} / \mathrm{He}$ carrier gas. 

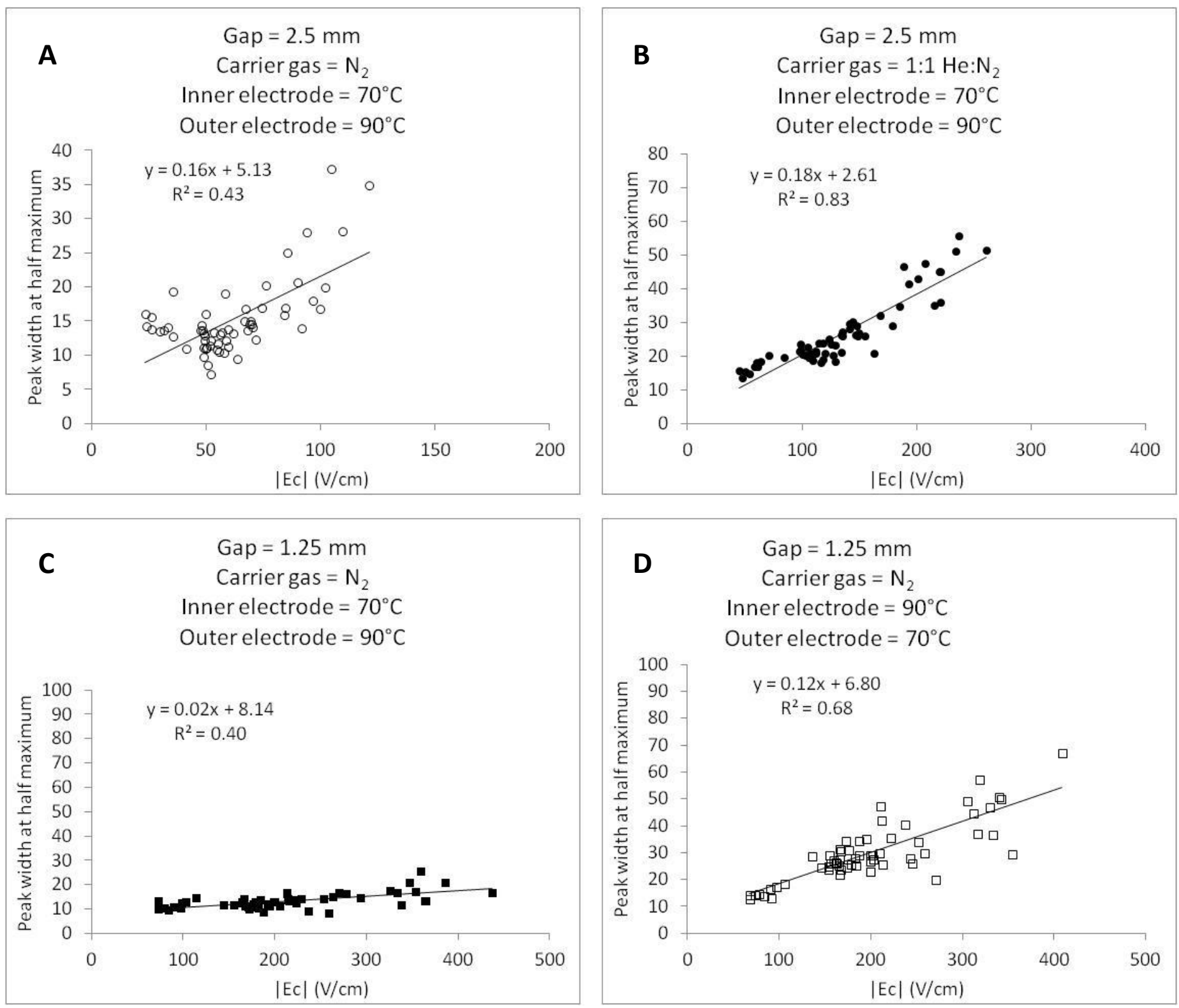

Figure S6. FAIMS peak width as a function of compensation voltage. The measured FAIMS peak width at half maximum $(w)$ was measured for 60 bovine serum albumin tryptic peptides using four different FAIMS configurations and plotted as a function of the compensation voltage of highest observed ion transmission for each ion. Compensation voltage is represented here as the magnitude of the compensation field, $\left|E_{C}\right|$. The abscissae and ordinates are scaled equally in the four plots in order to illustrate the differences in dependence of $w$ on $\left|E_{C}\right|$. The dependence of $w$ on $\left|E_{C}\right|$ was quasi-linear in all four FAIMS configurations, and was greatest in FAIMS configurations predicted to increase ion focusing. 


\section{Replicate nanoLC-MS injections provide few novel protein identifications}

Replicate nanoLC-MS/MS analyses of the same sample using DDA leads to new identifications due to the stochastic sampling of peptide ions. However, as we have demonstrated before (4), little new information is gained from more than a few replicate injections. For the unaided nanoLC-MS/MS analyses presented here, the yield of novel peptide identifications from a replicate nanoLC-MS/MS analysis dropped sharply after only a few replicate analyses (Figure S7). The second and third replicate injections increased the cumulative total of identified peptides by $17 \%$ and $7.0 \%$, respectively. The fourth replicate injection yielded only 546 new peptides (a $4.4 \%$ increase in cumulative novel identifications), and the eighth replicate injection yielded only 226 novel peptide sequences, a $1.6 \%$ increase in the cumulative total identifications. By comparison, the same amount of dedicated instrument time yielded significantly more identifications when FAIMS fractionation was employed. When the modified FAIMS electrodes were optimized for peak capacity, each subsequent nanoLC-FAIMS-MS/MS injection yielded thousands of new peptide sequences, and even the eighth and final injection yielded 2383 novel peptide sequences, increasing the cumulative total by $8.7 \%$. 


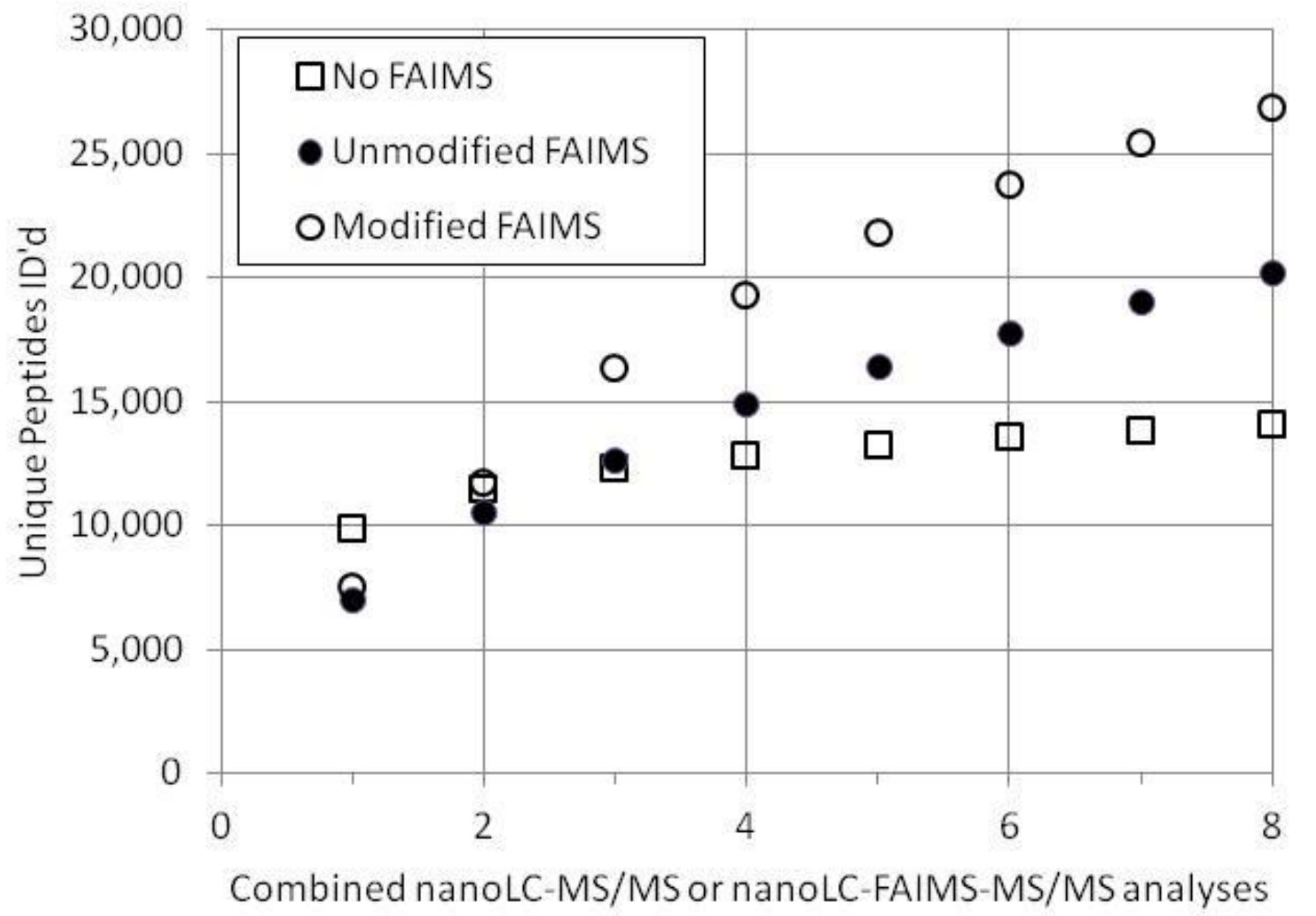

Figure S7. Accumulation of novel peptide identifications with replicate analyses. An unfractionated yeast tryptic digest was analyzed by nanoLC-MS/MS and nanoLC-FAIMS-MS/MS. Experiments with FAIMS combined eight separate nanoLC-FAIMS-MS/MS analyses, each performed at a different fixed compensation voltage. The experiment without FAIMS consisted of eight replicate nanoLC-MS/MS analyses. The total number of peptides identified for a given number of combined analyses is shown for nanoLC-MS/MS (open squares), nanoLC-FAIMS-MS/MS employing an unmodified cylindrical FAIMS device with an electrode gap of $2.5 \mathrm{~mm}$ and a mixture of $\mathrm{He}$ and $\mathrm{N}_{2}$ as the carrier gas (closed circles), and a modified FAIMS device with an electrode gap of $1.25 \mathrm{~mm}$ and pure $\mathrm{N}_{2}$ as the carrier gas (open circles). Both FAIMS configurations had the inner and outer electrodes at $70^{\circ} \mathrm{C}$ and $90^{\circ} \mathrm{C}$, respectively. The number of unique peptides identified with repeat injections decreases rapidly for unaided nanoLC-MS/MS. Adding FAIMS fractionation significantly increases the number of novel peptides identified for the same amount of instrument time. The modified FAIMS device provides the greatest increase in identifications. 


\section{Label-free quantification with FAIMS and isoelectric focusing}

Relative protein abundance was calculated in a label-free fashion for the proteins identified by OFFGEL electrophoresis isoelectric focusing (OGE), FAIMS, and no fractionation. The quantification technique, normalized spectral abundance factor (NSAF), estimates protein abundance as the SAF, which is calculated as the number of peptide spectrum matches associated with a given protein normalized to the protein's length (29-30). This SAF value is in turn normalized to the summed SAF values of all proteins identified from the sample, facilitating comparison between experiments and run conditions. SAF values for each protein were calculated using the number of high quality peptide spectrum matches (PSM) associated with the protein. A PSM was counted if it had an iProphet probability corresponding to a false positive error rate less than $1.0 \%$. Only non-degenerate peptides were counted, i.e., peptides that matched to only a single protein entry in the database. NSAF values were transformed by taking the natural log of the value in order to facilitate comparison and to reflect that fact that NSAF value increases in a logarithmic fashion with respect to protein concentration. Less negative InNSAF values correspond to higher protein concentrations.

NSAF values were compared between FAIMS and OGE fractionation as well as between FAIMS and the unfractionated analysis of the same sample (Figure S8). The NSAF values compared very well between FAIMS and OGE as evidenced by slopes at or near 1.0 and uniformly high $\mathrm{R}^{2}$ values. It is not surprising that deviation from the line of best fit increased at lower NSAF values; precision of NSAF decreases as the number of spectral counts approaches zero because a difference of even a single PSM (e.g., 2 spectra per protein versus 1 spectrum per protein) constitutes a proportionally large shift in estimated abundance compared with a small difference in a large number of spectra (e.g. 200 versus 199 spectra per protein).

Correlation was much poorer between the NSAF values from the unfractionated sample and those obtained from the OGE and FAIMS data sets. The correlation deviated from a slope of 1 as InNSAF values decreased. This trend likely arises from the fact that replicate data-dependent analyses of an unfractionated complex sample leads to the high abundance proteins being selected for fractionation over and over, whereas low abundance proteins are rarely sampled. This trend would lead to over-estimation of the spectral abundance of highly abundant proteins and underrepresentation of low abundance proteins. 

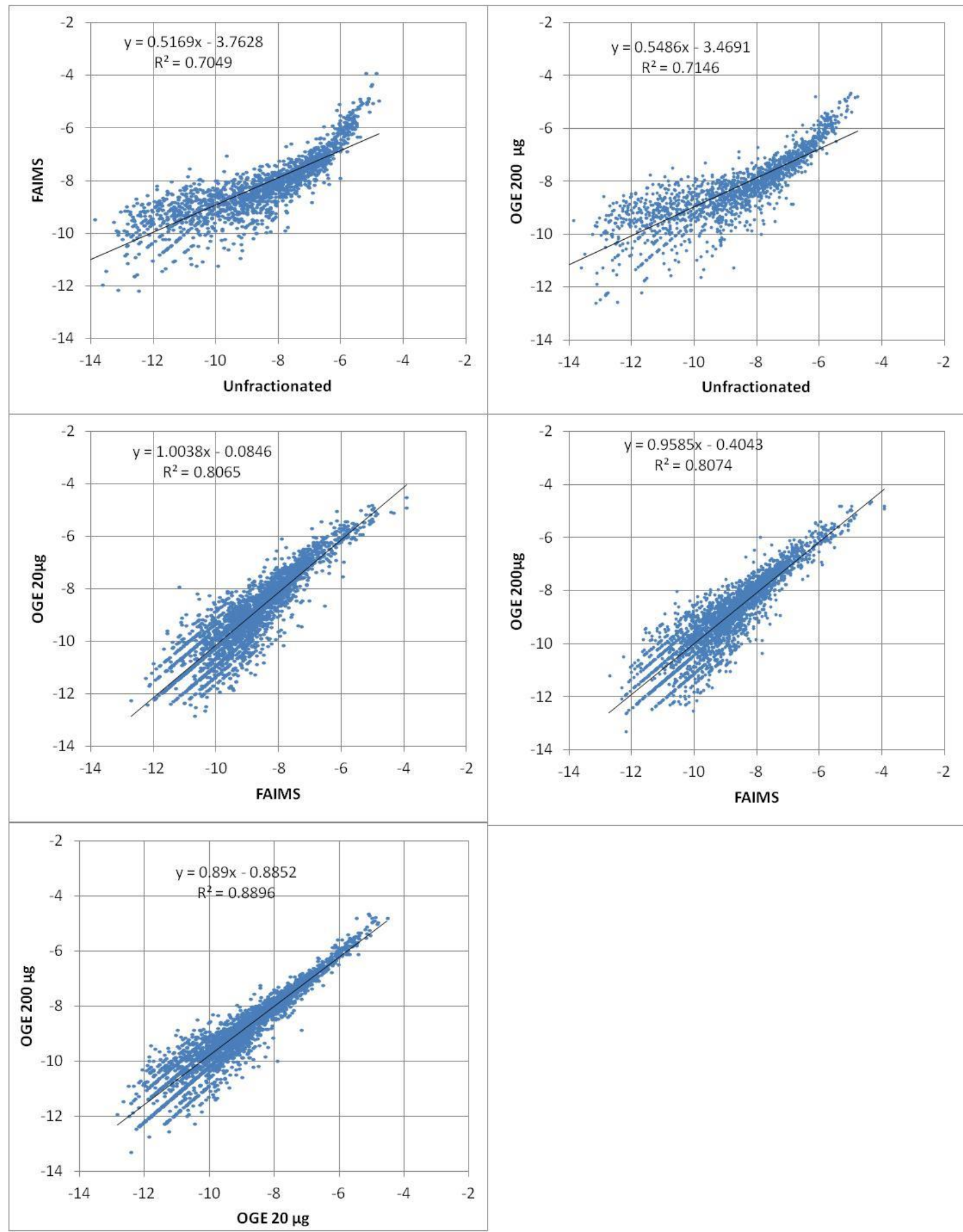

Figure S8. Comparison of normalized spectral abundance factor between sample fractionation techniques. 


\section{Supporting Information References}

1. Barnett, D. A., Belford, M., Dunyach, J. J., and Purves, R. W. (2007) Characterization of a temperature-controlled FAIMS system. J Am Soc Mass Spectrom 18, 1653-1663

2. Canterbury, J. D., Yi, X., Hoopmann, M. R., and MacCoss, M. J. (2008) Assessing the dynamic range and peak capacity of nanoflow LC-FAIMS-MS on an ion trap mass spectrometer for proteomics. Analytical chemistry 80,6888 6897

3. Barnett, D. A., and Ouellette, R. J. (2011) Elimination of the helium requirement in high-field asymmetric waveform ion mobility spectrometry (FAIMS): beneficial effects of decreasing the analyzer gap width on peptide analysis. Rapid Commun Mass Spectrom 25, 1959-1971

4. Swearingen, K. E., Hoopmann, M. R., Johnson, R. S., Saleem, R. A., Aitchison, J. D., and Moritz, R. L. (2012) Nanospray FAIMS fractionation provides significant increases in proteome coverage of unfractionated complex protein digests. Mol Cell Proteomics 11, M111 014985

5. Robinson, E. W., Sellon, R. E., and Williams, E. R. (2007) Peak deconvolution in high-field asymmetric waveform ion mobility spectrometry (FAIMS) to characterize macromolecular conformations. Int J Mass Spectrom 259, 87-95

6. Guevremont, R., and Purves, R. (2005) Comparison of experimental and calculated peak shapes for three cylindrical geometry FAIMS prototypes of differing electrode diameters. J Am Soc Mass Spectrom 16, 349-362

7. Guevremont, R., Thekkadath, G., and Hilton, C. K. (2005) Compensation voltage (CV) peak shapes using a domed FAIMS with the inner electrode translated to various longitudinal positions. J Am Soc Mass Spectrom 16, 948-956

8. Scherl, A., Shaffer, S. A., Taylor, G. K., Kulasekara, H. D., Miller, S. I., and Goodlett, D. R. (2008) Genome-specific gas-phase fractionation strategy for improved shotgun proteomic profiling of proteotypic peptides. Anal Chem $80,1182-$ 1191

9. Kessner, D., Chambers, M., Burke, R., Agus, D., and Mallick, P. (2008) ProteoWizard: open source software for rapid proteomics tools development. Bioinformatics 24, 2534-2536

10. Eng, J. K., Jahan, T. A., and Hoopmann, M. R. (2013) Comet: an open-source MS/MS sequence database search tool. Proteomics 13, 22-24

11. Deutsch, E. W., Mendoza, L., Shteynberg, D., Slagel, J., Sun, Z., and Moritz, R. L. (2015) Trans-Proteomic Pipeline, a standardized data processing pipeline for large-scale reproducible proteomics informatics. Proteomics Clin Appl

12. Deutsch, E. W., Mendoza, L., Shteynberg, D., Slagel, J., Sun, Z., and Moritz, R. L. (2015) Trans-Proteomic Pipeline, a standardized data processing pipeline for large-scale reproducible proteomics informatics. Proteomics Clin Appl 9, 745754

13. Nesvizhskii, A. I., Keller, A., Kolker, E., and Aebersold, R. (2003) A statistical model for identifying proteins by tandem mass spectrometry. Anal Chem 75, 4646-4658

14. Shvartsburg, A. A., and Smith, R. D. (2007) Scaling of the resolving power and sensitivity for planar FAIMS and mobility-based discrimination in flow- and field-driven analyzers. J Am Soc Mass Spectrom 18, 1672-1681

15. Shvartsburg, A. A., Tang, K., and Smith, R. D. (2005) Optimization of the design and operation of FAIMS analyzers. J Am Soc Mass Spectrom 16, 2-12

16. Creese, A. J., Shimwell, N. J., Larkins, K. P., Heath, J. K., and Cooper, H. J. (2013) Probing the complementarity of FAIMS and strong cation exchange chromatography in shotgun proteomics. J Am Soc Mass Spectrom 24, 431-443

17. Guevremont, R., Barnett, D. A., Purves, R. W., and Vandermey, J. (2000) Analysis of a tryptic digest of pig hemoglobin using ESI-FAIMS-MS. Anal Chem 72, 4577-4584

18. Kim, J. S., Monroe, M. E., Camp, D. G., 2nd, Smith, R. D., and Qian, W. J. (2013) In-source fragmentation and the sources of partially tryptic peptides in shotgun proteomics. J Proteome Res 12, 910-916

19. Xia, Y. Q., and Jemal, M. (2009) High-field asymmetric waveform ion mobility spectrometry for determining the location of in-source collision-induced dissociation in electrospray ionization mass spectrometry. Anal Chem 81, 78397843

20. Guevremont, R., and Purves, R. W. (1999) Atmospheric pressure ion focusing in a high-field asymmetric waveform ion mobility spectrometer. Rev Sci Instrum 70, 1370-1383 
21. Schneider, B. B., Covey, T. R., Coy, S. L., Krylov, E. V., and Nazarov, E. G. (2010) Planar differential mobility spectrometer as a pre-filter for atmospheric pressure ionization mass spectrometry. Int J Mass Spectrom 298, 45-54 22. Shvartsburg, A. A. (2009) Differential Ion Mobility Spectrometry, 1 Ed., CRC Press, Boca Raton, FL

23. Shvartsburg, A. A., Li, F., Tang, K., and Smith, R. D. (2006) High-resolution field asymmetric waveform ion mobility spectrometry using new planar geometry analyzers. Anal Chem 78, 3706-3714

24. Guevremont, R. (2004) High-field asymmetric waveform ion mobility spectrometry: a new tool for mass spectrometry. J Chromatogr A 1058, 3-19

25. Barnett, D. A., Ells, B., Guevremont, R., and Purves, R. W. (2002) Application of ESI-FAIMS-MS to the analysis of tryptic peptides. J Am Soc Mass Spectrom 13, 1282-1291

26. Shvartsburg, A. A., Tang, K., and Smith, R. D. (2004) Understanding and designing field asymmetric waveform ion mobility spectrometry separations in gas mixtures. Anal Chem 76, 7366-7374

27. Shvartsburg, A. A., Danielson, W. F., and Smith, R. D. (2010) High-resolution differential ion mobility separations using helium-rich gases. Anal Chem 82, 2456-2462

28. Shvartsburg, A. A., Ibrahim, Y. M., and Smith, R. D. (2014) Differential ion mobility separations in up to $100 \%$ helium using microchips. J Am Soc Mass Spectrom 25, 480-489

29. Zybailov, B., Mosley, A. L., Sardiu, M. E., Coleman, M. K., Florens, L., and Washburn, M. P. (2006) Statistical analysis of membrane proteome expression changes in Saccharomyces cerevisiae. J Proteome Res 5, 2339-2347

30. Gokce, E., Shuford, C. M., Franck, W. L., Dean, R. A., and Muddiman, D. C. (2011) Evaluation of normalization methods on GeLC-MS/MS label-free spectral counting data to correct for variation during proteomic workflows. J Am Soc Mass Spectrom 22, 2199-2208 